\title{
Novos Paradigmas para Especificação de Juntas Soldadas
}

\author{
(New Paradigms for Specification of Welded Joints)
}

\author{
Ivan Guerra Machado \\ Universidade Federal do Rio Grande do Sul, PPGE3M, Laboratório de Soldagem \& Técnicas Conexas \\ Porto Alegre, RS,Brasil,welder@ufrgs.br
}

\begin{abstract}
Resumo
O fim último da Tecnologia da Soldagem é a especificação da junta que será produzida. Isto inclui o seu dimensionamento, bem como a adequação de diversos fatores, tais como a tenacidade e outras propriedades mecânicas e metalúrgicas, o ambiente no qual ela está, além da sua finalidade. Porém, adicionalmente há uma nova tendência mundial —através de Códigos, normas etc.- de considerar a especificação da junta soldada como fruto de complexas interações entre os fenômenos metalúrgicos, os aspectos relativos aos mecanismos das conexões e o comportamento mecânico de todos os materiais envolvidos. Apesar de neste artigo considerarmos como metais base os aços estruturais, não há absolutamente perda de generalidade e com esta relativamente nova perspectiva, deverão sofrer profundas mudanças o nivel e a qualidade da informação usualmente acessível aos engenheiros de soldagem e aos projetistas de estruturas soldadas. Portanto, buscando alertar estes profissionais para os novos paradigmas, apresentaremos questões relativas ao projeto das estruturas soldadas (ou produzidas por brasagem), principalmente sob o ponto de vista do apoio que o engenheiro de soldagem pode oferecer ao projetista.
\end{abstract}

Palavras-chave: Soldagem e Brasagem, Projeto de Estruturas Soldada,. Especificação de Juntas Soldadas, Propriedades Mecânicas e Metalúrgicas.

\begin{abstract}
The paramount aim of Welding Technology is the specification of the joint that will be produced. This includes its dimensioning, as well as the suitability of many factors, such as toughness and other mechanical and metallurgical properties, the environment in which it is, besides its fitness for purpose. However, additionally there is a new world-wide trend - through Codes, standards etc. - in to consider the welded joint specification as a result of complex interactions among the metallurgical phenomena, the aspects related to connections mechanisms and the mechanical behaviour of all materials involved. In despite of in this paper we consider structural steels as base metals, absolutely there is not lack of generality and with this relatively new outlook, it is expected that profound changes will occur in the level and quality of the information usually accessible to welding engineers and designers of welded structures. Therefore, aiming to caution those professionals to the new paradigms, we will pose questions related to the design of welded structures (or produced by brazing), mainly under the point of view of the support that the welding engineer can offer to the designer.
\end{abstract}

Key-words: Welding and Brazing, Design of Welded Structures, Specification of Welded Joints, Mechanical and Metallurgical Properties.

\section{Introdução}

O objetivo maior da Ciência e Tecnologia da União dos Materiais —ou da Soldagem, se admitirmos um significado mais abrangente para esta palavra - é a especificação das juntas soldadas sobre estruturas úteis à sociedade e que cumpram com aquelas finalidades para as quais foram idealizadas. $\mathrm{O}$ dimensionamento destas juntas sobre aços estruturais - tema que abordamos parcialmente em artigo nesta revista [1] — apesar de sumamente importante, é somente parte deste problema.

A grande questão, é que está ocorrendo um movimento mundial (através de Códigos, normas etc.), por enquanto ainda quase imperceptível, no sentido de considerar a especificação da

(Convidado em 15/05/2012; Texto final em 30/08/2012). junta como fruto de complexas interações entre os fenômenos metalúrgicos, os aspectos relativos aos mecanismos das conexões e o comportamento mecânico de todos os materiais envolvidos. Entretanto, infelizmente verificamos que muitos profissionais atuantes nesta área no nosso país ainda não perceberam este fato.

Desta forma, como direta consequência da alteração no modo do tratamento desta questão, deverão sofrer profundas mudanças o nível e a qualidade da informação usualmente acessível aos engenheiros de soldagem e projetistas de estruturas soldadas. Este novo paradigma somente será vencido, se estes profissionais receberem formação muito mais completa e profunda, tanto com relação às interações entre metalurgia e mecânica, quanto aos princípios fundamentais do projeto das estruturas metálicas, além do deveras importante quesito, que é aprender a trabalhar em conjunto.

Nesta abordagem de assuntos com grande abrangência, discutiremos qualitativamente os principais aspectos envolvidos 
e não nos deteremos em questões pontuais. Isto implica que deixaremos de comentar, por exemplo, as inter-relações das inclusões e microestruturas do metal de solda, ou efeitos da taxa de resfriamento sobre eles e a zona afetada pelo calor, em relação às propriedades mecânicas da junta soldada. Estes são temas específicos, vinculados com procedimentos e metalurgia da soldagem, cuja análise detalhada foge do escopo deste artigo.

Então, apresentaremos aspectos relativos ao projeto das estruturas soldadas, mas sob o ponto de vista do apoio que o engenheiro de soldagem pode oferecer ao projetista. Após, discutiremos questões envolvendo interações mecânicas e metalúrgicas pertinentes às juntas soldadas estruturais sendo, no nosso entender, de fundamental importância que estes profissionais percebam as sutis nuances existentes neste assunto.

\section{Projetos Globais e Falhas Estruturais}

Muitas organizações —dentre elas várias brasileirasprojetam e constroem estruturas soldadas em ambientes tão distintos quanto aqueles encontrados no Amazonas, na Sibéria ou no Saara. Estas estruturas podem sofrer solicitações inesperadas, pois o projeto talvez não contemple completas previsões para ambientes extremos, além da intervenção humana, tal como sabotagem, entre outros casos.

Por outro lado, algumas práticas de projeto tendem a idealizar estruturas e condições de carregamento, bem como espécimes para ensaios de fratura usualmente minimizam o espectro de falhas e níveis de tensões aplicáveis. Adicionalmente, há a concepção generalizada do metal como uma entidade isotrópica e homogênea, submetida a índices específicos de tenacidade à fratura altamente acurados.

Porém, no "mundo real" as estruturas não "obedecem" exatamente as idealizações de projeto, as descontinuidades são inevitáveis e os materiais encontram-se distantes da isotropia ou da homogeneidade. Além disto, é considerável a influência do "fator humano", incluindo questões relativas à ética e acidentes. Por exemplo, quando as falhas têm como causa "os engenheiros", um estudo do Instituto Federal Suíço de Tecnologia [2] identificou vários fatores, com $43 \%$ deles sendo devido ao conjunto "esquecimento e erro"; "ignorância, desatenção, negligência" e "influência subestimada". Porém, sem dúvida é alarmante que $36 \%$ destas falhas originam-se exclusivamente do item "insuficiente conhecimento do engenheiro" (!) sendo isto extremamente preocupante, principalmente para os usuários das estruturas por eles projetas...

Talvez na atualidade não seja possível, ou mesmo desejável a aplicação do conhecido Código de Hammurabi —o sexto rei da Babilônia, que viveu entre aproximadamente 1792 e 1750 a. C.. Além da clássica passagem do "um olho por um olho, um dente por um dente...", parte deste Código, de direto interesse para os engenheiros, começa ditando mais ou menos o seguinte [3]: (a) se um construtor constrói uma casa para um homem e não faz a sua construção firme e a casa a qual ele construiu colapsa e causa a morte do proprietário da casa, o construtor deve ser morto; (b) se isto causa a morte do filho do proprietário da casa, deverá ser morto o filho daquele construtor... Certamente, porém, deveria ser muito mais rigorosamente aferido o conhecimento dos engenheiros candidatos a projetar e soldar estruturas metálicas.

Como qualquer outro componente estrutural, juntas soldadas falham em serviço, principalmente em função do ambiente de operação e da natureza da carga aplicada, sendo usuais as seguintes situações: falha por excessivo carregamento através de mecanismos de fratura "frágil" (clivagem ou quase clivagem); falha por excessivo carregamento através de mecanismos de fratura dúctil (coalescência dos vazios); colapso plástico; flambagem; fadiga; corrosão fadiga; corrosão; trinca por corrosão sob tensão; trinca induzida pelo hidrogênio (ou, ainda, outros defeitos com origem em fenômenos metalúrgicos). Caso relativamente altas temperaturas estejam envolvidas, devem ser ainda consideradas a deformação por fluência e a fratura por tensão.

Os primeiros 4 modos de falha ocorrem sob carregamento estático. Fratura dúctil, colapso plástico e flambagem são geralmente precedidos de significativa deformação plástica, a qual pode emitir algum sinal ou indicação antes da falha final. Em contraste, a propagação frágil de trinca não apresenta apreciável deformação macroscópica e pode levar a seu rápido (e instável) crescimento, com súbita falha geralmente catastrófica.

Fraturas frágeis de estruturas soldadas podem ser dramáticas, geralmente levando a sérias consequências e talvez os mais conhecidos e clássicos exemplos são os navios da classe "Liberty Ships" [4]. Com projeto original britânico e até pouco antes da $2^{\text {a }}$ Guerra Mundial rebitados, cada unidade era produzida em cerca de 1 ano. Não existem relatos de graves falhas estruturais neste modelo. Entretanto, em 1941 o projeto destes navios foi ligeiramente alterado e, também, eles passaram a ser fabricados nos E.U.A. em grande parte por soldagem, na taxa média de 1 unidade a cada 42 dias - foram construídos mais de 5.000 navios durante a guerra. A partir de então ocorreram em torno de 1.500 fraturas frágeis significativas, algumas catastróficas, sendo que $40 \%$ destas falhas iniciaram em defeitos nas juntas soldadas (trincas, mordeduras e falta de fusão) e 10\% derivaram de defeitos na zona afetada pelo calor e outros entalhes, com o restante $50 \%$ desde concentradores de tensão, tais como laterais das escotilhas em ângulo reto.

Descobriu-se que muitos incidentes ocorreram devido ao efeito das baixas temperaturas do Mar do Norte, as quais podem ser inferiores à temperatura de transição da fratura de dúctil para frágil no aço então utilizado - ele apresentava resistência ao impacto de somente $20 \mathrm{~J}$ a $4{ }^{\circ} \mathrm{C}$. Maiores detalhes foram ainda obtidos, pelo estudo das causas que provocaram a fratura transversal do navio Schenectady, quando atracado no porto de Portland (E.U.A.) em janeiro de 1943, num dia de temperatura amena e mar calmo. Neste caso, as fraturas originaram-se em descontinuidades na junta soldada e se propagaram através da chapa de aço ao carbono, cuja microestrutura era perlita "grosseira" produzida por recozimento. A existência de tal microestrutura mostrou-se como condição essencial para a ocorrência das fraturas frágeis experimentadas pelos "Liberty Ships". Estas falhas foram minimizadas através de tratamento térmico de normalização das chapas, com a perlita "fina" apresentando muito maior tolerância ao início de trincas nas descontinuidades das soldas.

Por outro lado, existindo carregamento cíclico, a fadiga 


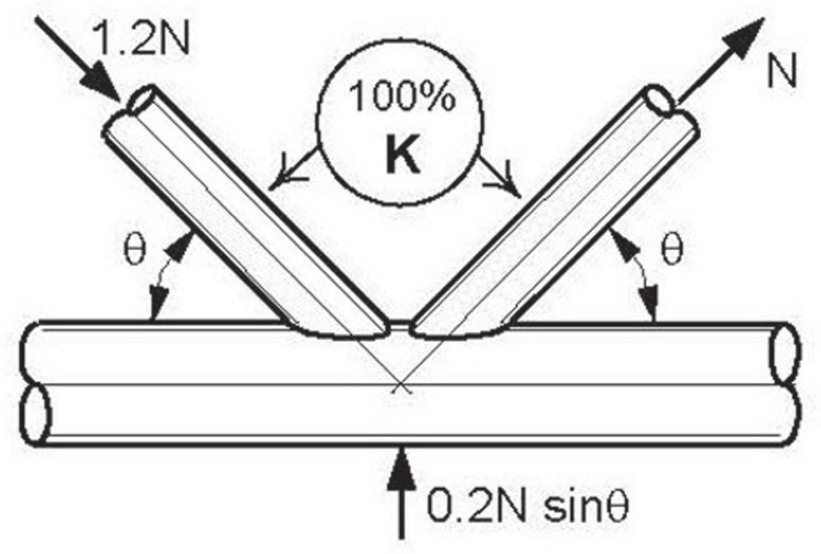

(a)

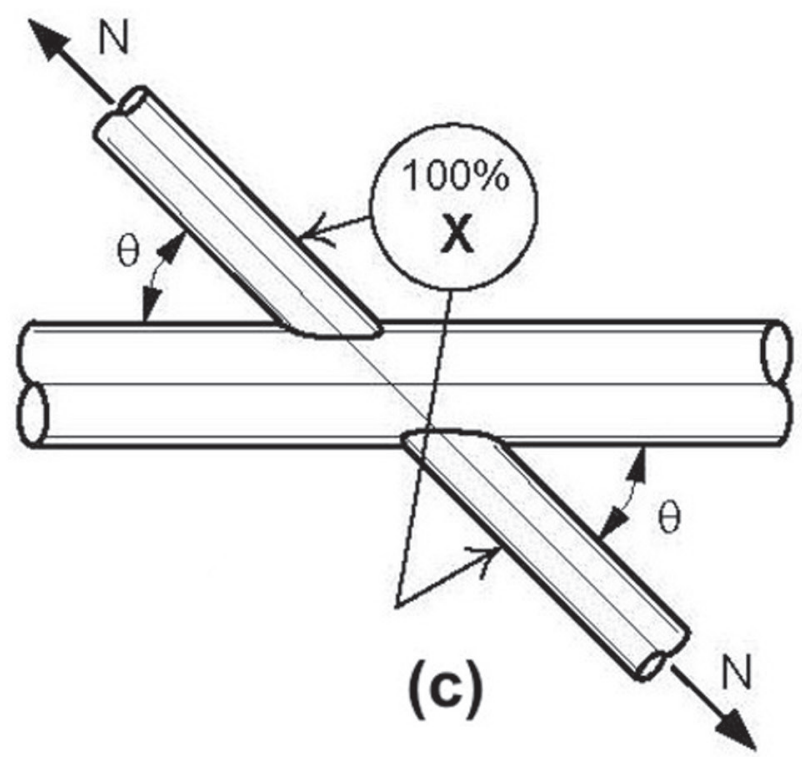

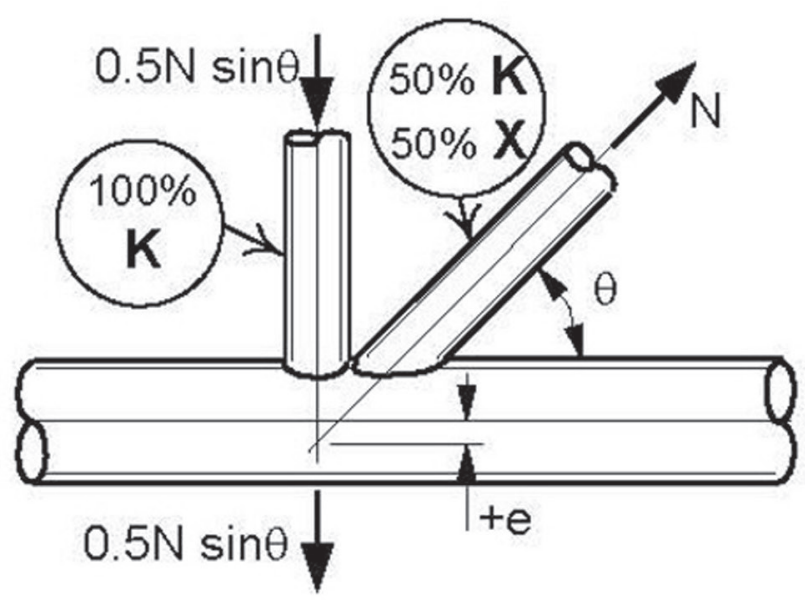

(b)

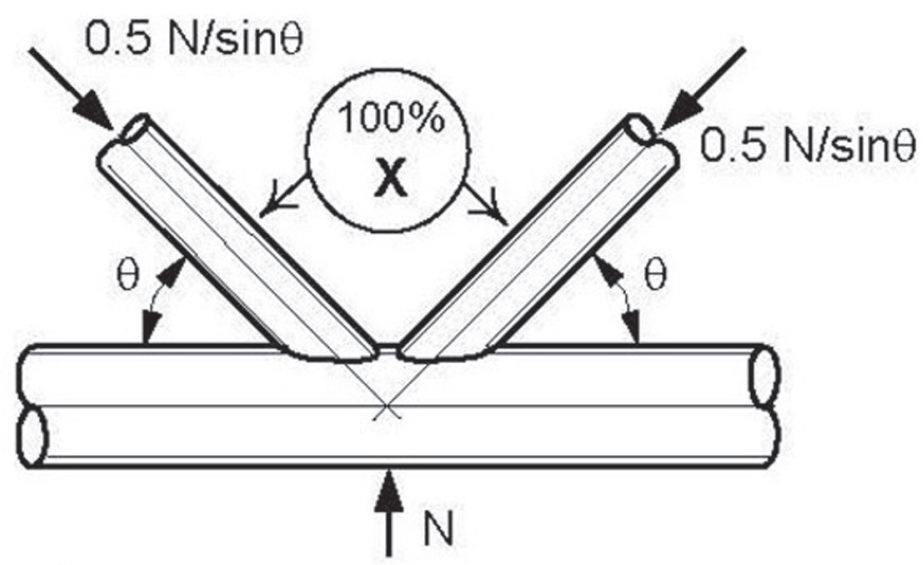

(d)

Figura 1. Estruturas tubulares: a classificação dos membros é determinada pelo método da transferência de forças na junta.

é aspecto muito importante a ser considerado nas estruturas soldadas, pois as juntas naturalmente são descontinuidades (geométricas) e, assim, sítios potencialmente perigosos para iniciar trincas. Além disto, as juntas soldadas são determinantes no intervalo máximo de tensão para um dado número de ciclos, que toda a estrutura pode sofrer [5]. Por exemplo, a 2 milhões de ciclos, uma chapa ou perfil laminados de aço estrutural possui intervalo máximo de tensão admissível de $166 \mathrm{MPa}$, enquanto que basta uma junta à topo transversal à carga aplicada, para reduzir esta tensão para meros $69 \mathrm{MPa}$. Também é usual as juntas (ou "detalhes") serem classificadas em "Categorias". Neste caso, a máxima tensão admissível em fadiga de um duto circular laminado é mais do que o dobro de quando ele é soldado à topo, ou um duto retangular com flange soldado é 4,4 vezes menor do que quando não soldado.

Com relação a este tipo de falha, é exemplar o acidente em 1980 da plataforma de perfuração parcialmente submersa
Alexander L. Kielland, no campo de petróleo Ekofisk na Noruega [6, por exemplo]. O colapso ocorreu devido a propagação por fadiga de trinca induzida pelo hidrogênio na zona afetada pelo calor e inaceitável perfil de uma solda de filete produzida entre flange e um braço, além da existência de decoesão lamelar na chapa do flange, o qual continha um dispositivo de sonar e não suportava carga. Além da bilionária perda, morreram 123 pessoas e no Museu do Petróleo Norueguês pode ser visto parte do braço que falhou, tal como uma muda testemunha denunciando erros cometidos pelos homens.

Por sua vez, o fenômeno corrosão apresenta certa ambiguidade, pois eventualmente um metal base que é resistente a dado ambiente, quando soldado passa a sofrer seus efeitos. Entretanto, em muitas ocasiões a junta soldada mostra-se mais resistente do que o metal base, ou ainda, a resposta é errática. Esta é uma área que requer ainda muita investigação. 


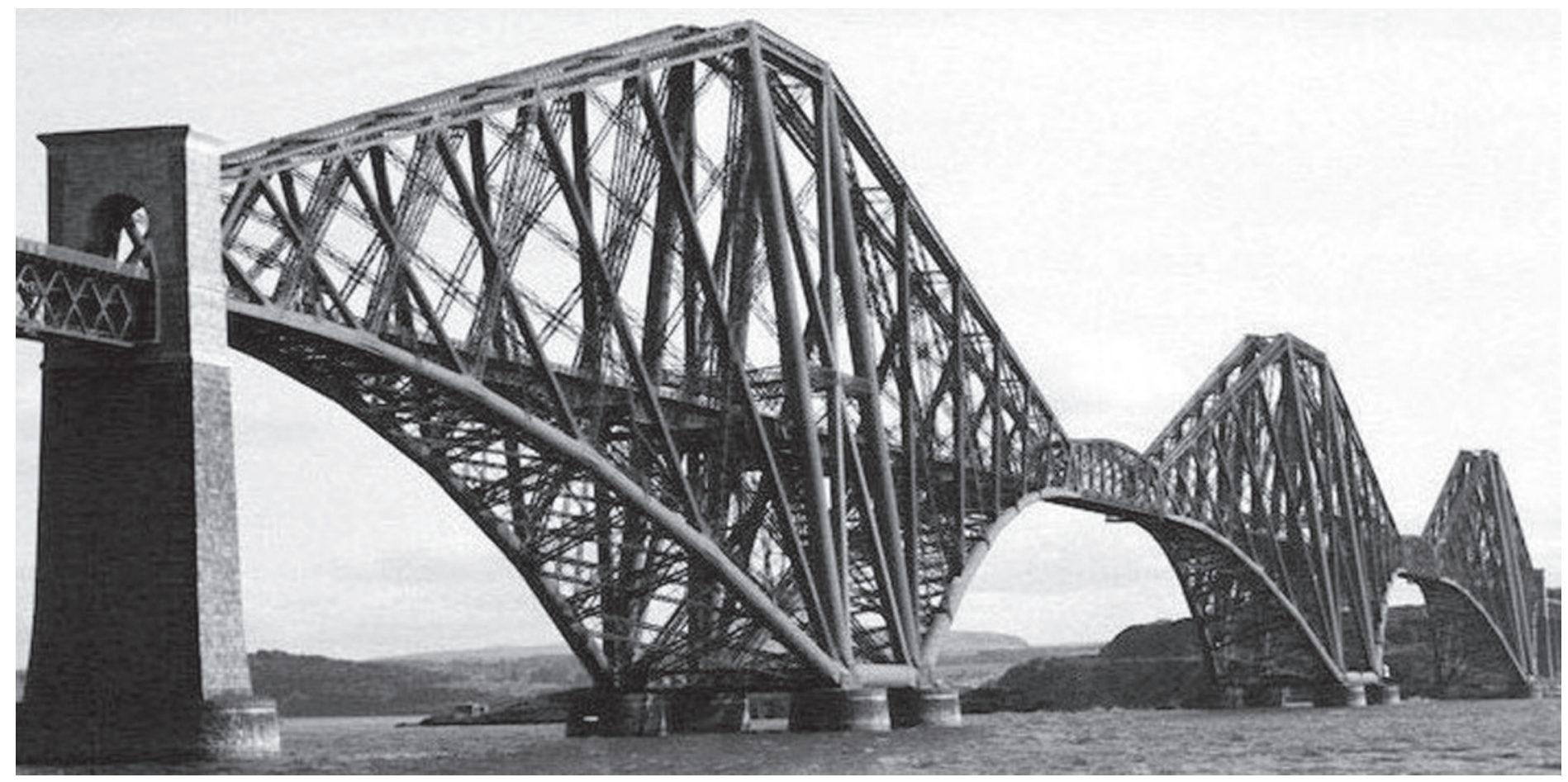

Figura 2. Ponte Firth of Forth (Escócia).

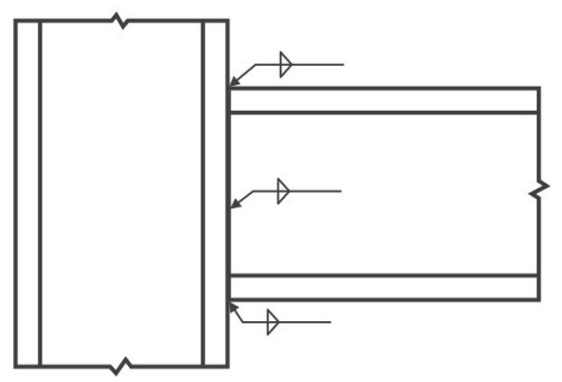

(a)
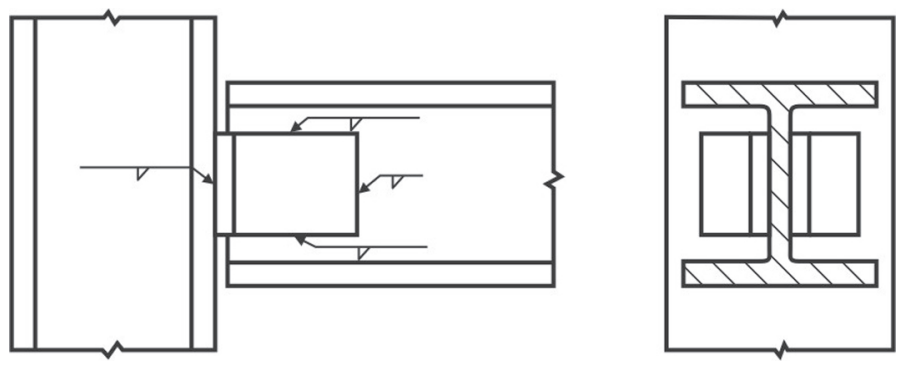

(b)

Figura 3. Conexão entre coluna e viga do tipo rígida (a) e flexível (b).

\section{Modernos Conceitos: Configurações e Rigidez das Juntas Soldadas Estruturais}

Diversas normas ou Códigos $[5,7,8]$ permitem o dimensionamento das juntas soldadas com base no seu tipo, principalmente aquelas à topo, ou em "T" e a seção resistente aos esforços resulta do produto da garganta pelo comprimento da solda. O dimensionamento pressupõe tensão de cisalhamento somente sobre o plano determinado pela garganta, independentemente da direção da carga atuante -maiores informações em [1].

Entretanto, nos últimos anos vêm sendo reforçada a tendência da classificação das juntas soldadas com base na sua função e posição na estrutura $[9,10]$. Assim, a conexão é o "local no qual dois ou mais elementos se encontram" e a junta o "local onde dois ou mais membros são interconectados", sendo dimensionados de formas diferentes. Por exemplo, no caso de edifícios de aço soldados, há distinção entre conexões de viga e coluna com configuração simples e dupla, além dos tipos e posições dos membros que estão sendo conectados.

Similarmente, as normas e Códigos que tratam de estruturas com membros tubulares, de há muito consideram que a classificação dos membros é determinada pelo método da transferência de forças na junta, não pela sua aparência física. Então, no caso da Figura 1 [11], ambos os membros em (a) são do tipo "K"; em (b) um membro é $100 \%$ "K" e o outro é $50 \%$ "K" e $50 \%$ " $X$ "; além disto, os membros em (c) são claramente 100\% " $\mathrm{X}$ ", mas também o são aqueles em (d). A maior consequência desta classificação, é que membros com distintas transferências de forças na junta devem ser dimensionados diferentemente. Esta situação encontra grande aplicação nas estruturas offshore, onde é comum a ocorrência de juntas soldadas complexas.

Porém, muito antes de existirem normas ou Códigos regrando estas questões, engenheiros de elevada capacidade (e, acreditamos, também extremamente autoconfiantes...) projetaram e construíram grandes estruturas. Um exemplo é a 
colossal ponte de Firth of Forth (Figura 2), erigida na Escócia em 1890, com comprimento maior do que $2.500 \mathrm{~m}$ e vão livre de $521 \mathrm{~m}$, cujos membros tubulares foram produzidos desde chapas calandradas e rebitadas (cerca de 7 milhões de rebites...), pois a soldagem ao arco elétrico estava na sua infância. Aliás, esta foi uma das primeiras estruturas metálicas de muito grande porte no mundo a empregar em larga escala o princípio da viga em balanço.

No moderno conceito de projeto, as juntas soldadas são consideradas componentes estruturais, tais como colunas e vigas, com propriedades de rigidez, resistência e capacidade de deformação. Portanto, considerações sobre estas juntas devem ser realizadas conjuntamente com aquelas dos componentes estruturais.

Em geral, entre partes de equipamentos e máquinas, ou em estruturas metálicas específicas, devido às pequenas tolerâncias na montagem, as juntas soldadas transmitem diretamente a carga aplicada, sem nenhum elemento intermediário, sendo consideradas "rígidas", conforme Figura 3(a). Entretanto, em certas condições algumas precauções devem ser tomadas, tal como evitar a flexão da mesa do perfil da coluna.

Porém, na maioria das grandes estruturas metálicas é impossível manter estreitas tolerâncias. Então, a transferência de carga é realizada indiretamente entre as juntas através de elementos intermediários, sendo consideradas nominalmente "flexíveis" e com possibilidade de apresentar diversas configurações, tal como na Figura 3(b).

$\mathrm{Na}$ realidade, não existem juntas completamente "rígidas" ou totalmente "flexíveis" e a grande questão é a determinação do mais próximo valor da verdadeira "ductilidade" da conexão. Este tópico encontra diferentes conceituações entre normas e Códigos.

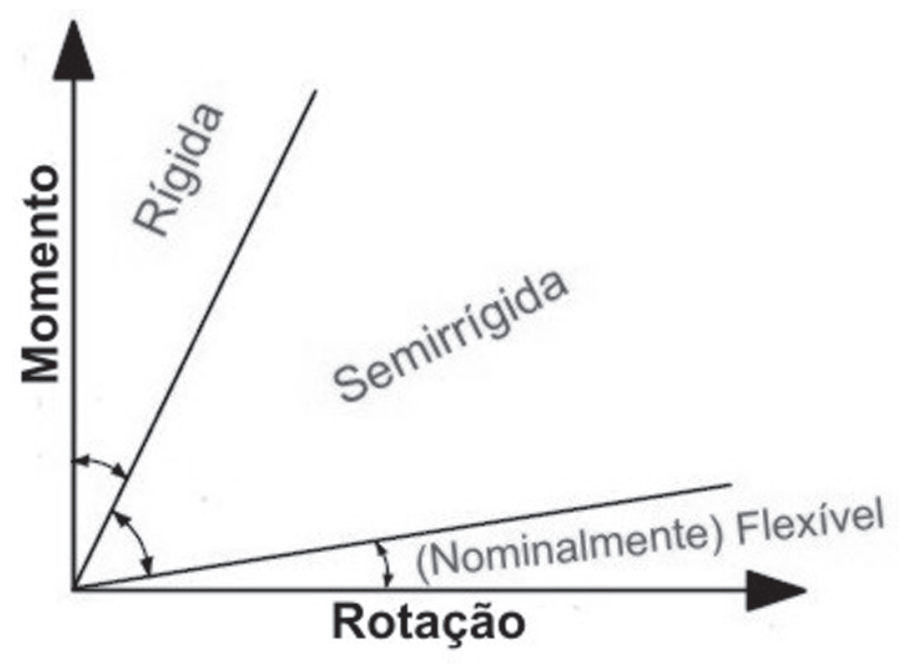

Figura 4. Tipos esquemáticos de conexões entre coluna e viga.

Além disto, as forças e deformações empregadas no projeto da estrutura devem ser consistentes com as premissas usadas na análise estrutural e a performance pretendida das conexões. Entre coluna e viga, por exemplo, a conexão pode ser dos seguintes tipos (Figura 4): (a) flexível, ou seja, o momento transmitido é desprezível; (b) semirrígida, em que há transferência dos momentos, mas a rotação entre os membros conectados não é desprezível e a conexão poderá apresentar resistência maior do que a viga; (c) rígida, a qual transmite momento com desprezível rotação entre os membros conectados.

Um fato que torna ainda mais complexa a colaboração entre o engenheiro de soldagem e o projetista da estrutura, é os projetos poderem ser conceitualmente muito diferentes. O projeto que utiliza resistência (ou tensão) admissível é caracterizado pelo uso de cargas de serviço não decompostas, em conjunto com um único "fator de segurança" aplicado à resistência admissível. Porém, o projeto baseado em fator de carga e resistência, emprega o conceito dos estados limites, ou seja, a condição na qual uma estrutura ou parte dela não mais desempenha sua função (estado limite da prestação de serviço) ou alcançou sua máxima capacidade de suportar carga (estado limite da resistência). Entretanto, nem todas as normas ou Códigos relativos à soldagem aceitam ambos os critérios.

\section{Ductilidade "por Projeto"}

Outro importante aspecto que deve ser considerado é o excessivo constrangimento dos membros da estrutura, ou das juntas soldadas, seja devido a inesperadas condições de serviço ou situações criadas pelo próprio projetista.

Uma das prováveis razões para o projetista provocar este constrangimento, é o absolutamente equivocado entendimento —infelizmente ainda generalizado-, de que sendo um material dúctil no ensaio de tração convencional, ele assim se comportará em praticamente qualquer situação (na mesma temperatura do ensaio). Entretanto, neste caso o material é livre para se deformar, com a tensão normal ou de tração resultante da força aplicada produzindo tensão de cisalhamento, cujo máximo ocorrerá a $45^{\circ}$ da direção da força. Se a tensão de cisalhamento exceder certo "valor crítico", devido aos deslizamentos dos planos cristalográficos há apreciável alongamento do corpo de prova. A este valor crítico denominamos "limite de escoamento" $\left(f_{y}\right)$.

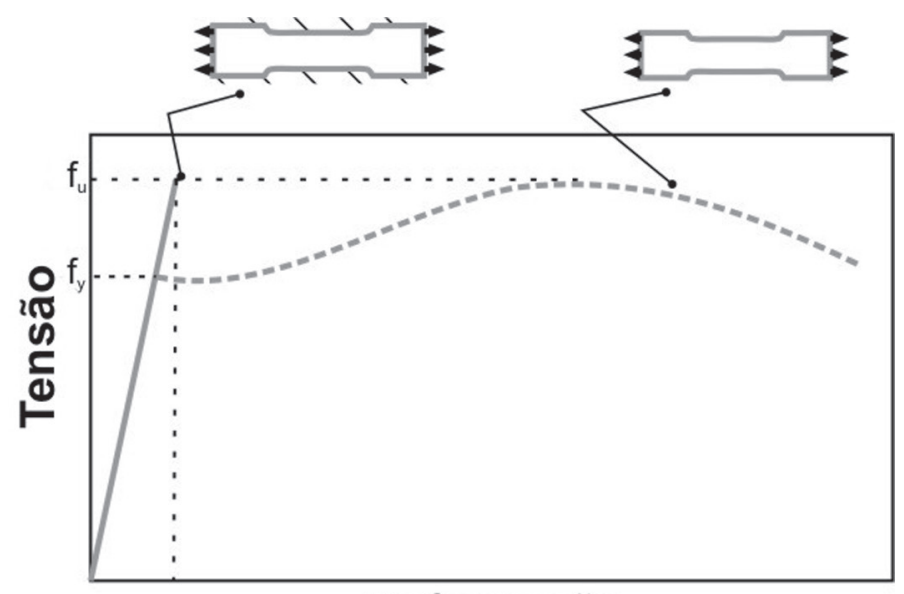

Deformação

Figura 5. Ensaio de tração convencional, com e sem constrição do espécime. 

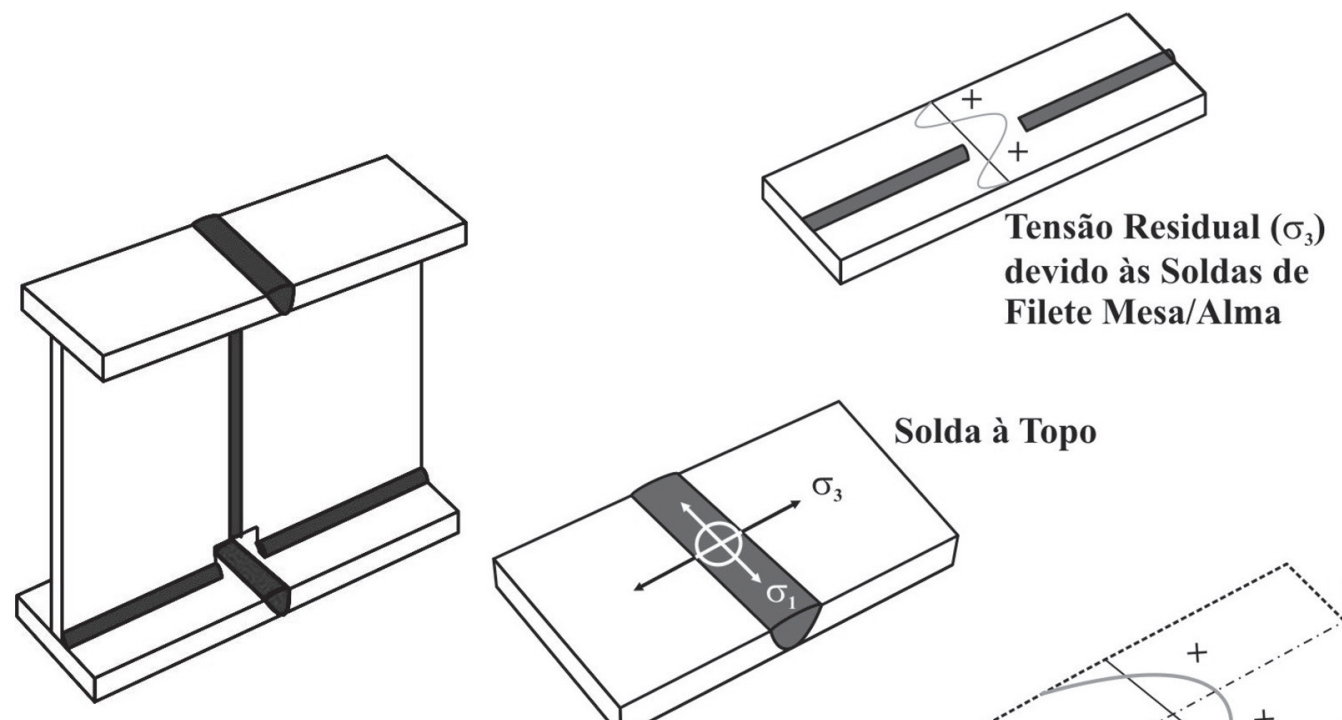

\section{Tensão Residual} Transversal $\left(\sigma_{1}\right)$

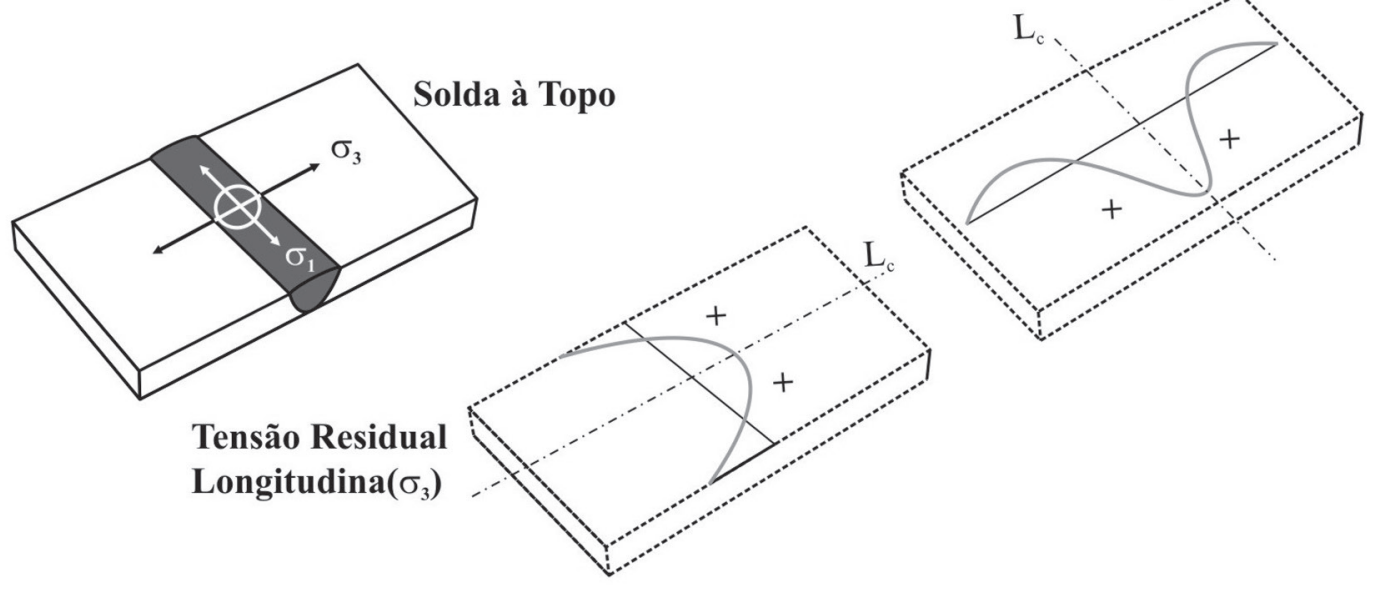

Figura 6. Tensões residuais em vigas soldadas à topo.
Porém, esta situação praticamente inexiste no "mundo real" e ductilidade não é uma propriedade mecânica "líquida e certa", mas ocorrerá, pelo menos, se: (a) existir tensão de cisalhamento resultante da carga aplicada; (b) esta tensão de cisalhamento exceder razoavelmente o valor crítico, sendo que quanto mais o exceder, maior será a ductilidade; (c) a deformação plástica — que resulta da tensão de cisalhamento-, agir numa direção que alivie a particular tensão atuante; (d) o membro submetido a carregamento possuir suficiente volume não constrangido, capaz de sofrer deformação.

Então, caso as duas primeiras condições não sejam satisfeitas, a ductilidade deixará de se manifestar-consequentemente, também não existirá escoamento-, com a tensão aplicada simplesmente aumentando até o (limite) da resistência à tração do aço $\left(f_{u}\right)$, com muito pouca ou nenhuma energia plástica absorvida e a fratura será frágil. Portanto, basta o (simples) corpo de prova deste ensaio uniaxial e não constrangido sofrer restrição à deformação numa direção, para ser alta a probabilidade dele fraturar subitamente, conforme mostramos na Figura 5.

Similarmente, membros de grandes estruturas fabricados com aço usualmente dúctil em tensão de tração, podem comportar-se de forma frágil, bastando que certas situações de carregamento produzam constrangimento excessivo, mesmo que parcialmente, ou se uma dada seção transversal tem sua resistência reduzida, por exemplo através de furos, de forma que esta seção falha antes que o membro sofra escoamento.

Um caso típico e clássico [12] é aquele da abertura de acesso quando duas partes de vigas são soldadas (Figura 6), sendo a última junta produzida aquela à topo entre as mesas (inferiores, na figura). Nesta situação, previamente foram produzidas tensões residuais pelas juntas de filete entre mesas e almas (de ambas as partes); adicionalmente, desenvolvem-se tensões residuais devido às juntas soldadas à topo entre as mesas. Muitas normas e Códigos determinam valores para a distância da abertura de acesso até o pé da solda à topo e altura da abertura de acesso, geralmente em função da espessura da alma da viga. No caso da largura do acesso ser demasiadamente estreita, a alma na sua extremidade encontra-se excessivamente próxima da junta soldada e numa região em que a tensão residual é de tração; assim, há constrangimento à deformação na direção da espessura da mesa, com a correspondente tensão podendo ser relativamente elevada. Desta forma, o projetista criou uma situação na qual poderá ocorrer fratura frágil.

Por outro lado, sendo o acesso mais largo, a extremidade da alma nesta abertura está afastada do cordão de solda e encontrase submetida à tensão residual de compressão transversal $\left(\mathrm{s}_{1}\right)$ e de tração longitudinal $\left(s_{3}\right)$, resultando em alta ductilidade, pois existe condição para deformação plástica na direção da espessura da mesa.

Esta questão é complexa e estruturas que sofrerão grandes solicitações durante a sua construção ou em serviço, geralmente serão fabricadas atendendo uma série de requisitos, os quais, no mínimo, são os seguintes [9]:

(i) Quanto à ductilidade: (a) razão entre o limite de escoamento e a resistência à tração menor ou igual a 0,91 para edificações metálicas, ou 0,85 para estruturas offshore; (b) alongamento na ruptura maior do que 15\%; (c) deformação correspondente à máxima resistência à tração maior do que 15 vezes aquela correspondente ao limite de escoamento.

(ii) A tenacidade deve ser suficiente para evitar fratura frágil de elementos em tensão de tração, na menor temperatura de serviço esperada. 


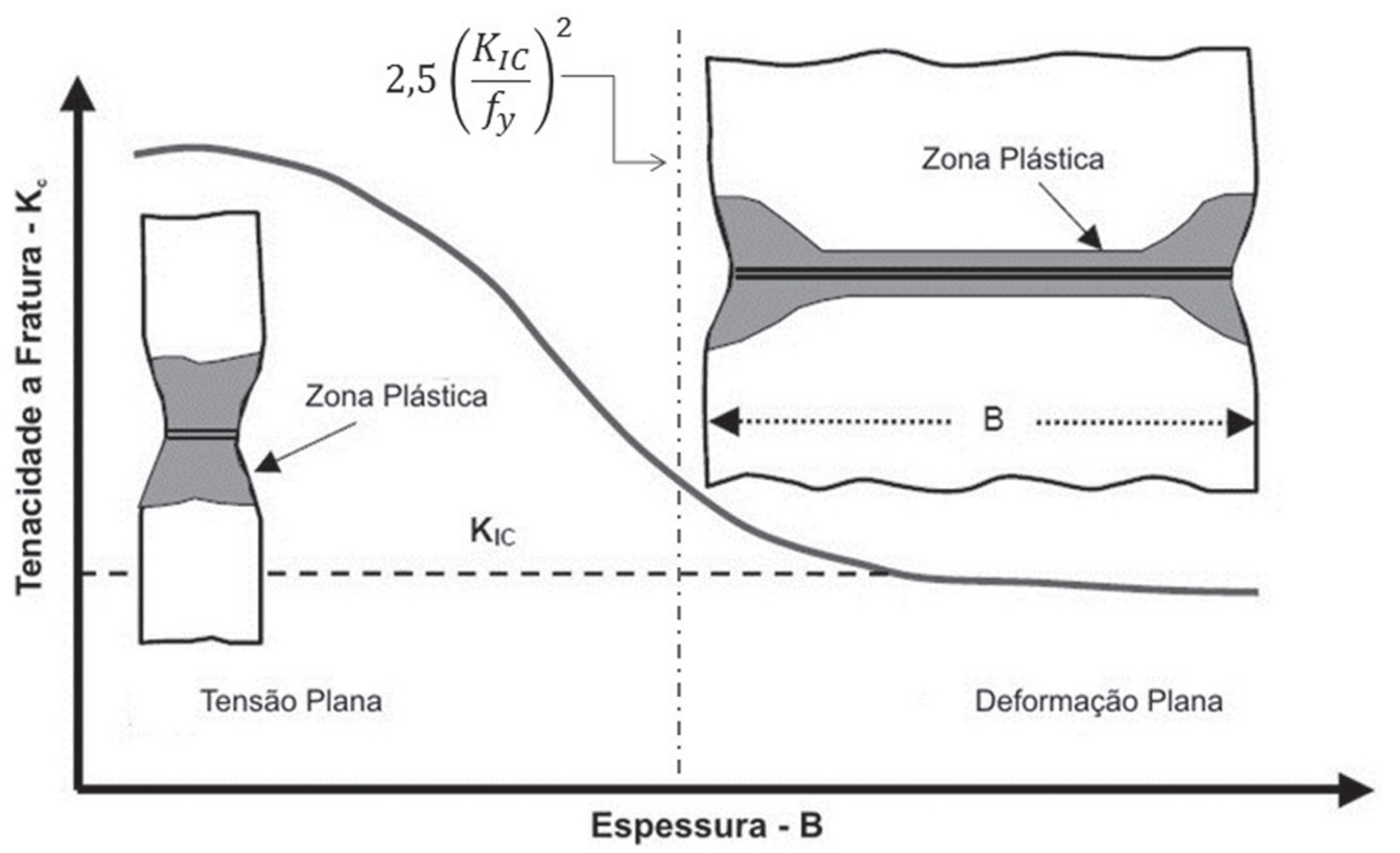

Figura 7. Tenacidade à fratura em função da espessura do aço ( $\mathrm{f}_{\mathrm{y}}=$ limite de escoamento; $\mathrm{K}_{\mathrm{IC}}=$ tenacidade à fratura em deformação plana).

(iii) A espessura de cada membro é limitada pelo tipo de aço, temperatura de operação e probabilidade da ocorrência de decoesão lamelar.

Tendo em vista tais exigências, é justa a pergunta: por que tantas precauções?

Claramente, não há uma resposta única para esta questão, mas um conjunto de fatores que devem ser satisfeitos, entre os quais se encontram os seguintes:

(i) Diversos estados de tensão podem ocorrer, alguns inesperados se as condições de carregamento não são exatamente conhecidas. Além disto, há de se considerar a alteração do modo de tensão plana em relativamente pequenas espessuras, para o de deformação plana com maiores espessuras e consequente redução da tenacidade, conforme ilustramos na Figura 7. Salientamos que a espessura limítrofe é inversamente proporcional ao quadrado do limite de escoamento do aço. Portanto, em geral, a combinação de metal base com muito alta resistência mecânica e grande espessura, é prenúncio de possível tragédia.

(ii) Com carga estática, em geral quanto maior o limite de escoamento de um aço estrutural, tanto menor o seu alongamento e, consequentemente, a sua ductilidade. Além disto, conforme aumenta a sua resistência à tração, menor será a deformação verdadeira a ela associada.

(iii) As juntas soldadas também sofrem redução da sua capacidade de deformação, conforme são empregados metais de adição com maior resistência e este fato tem profundas implicações, como mostraremos adiante.

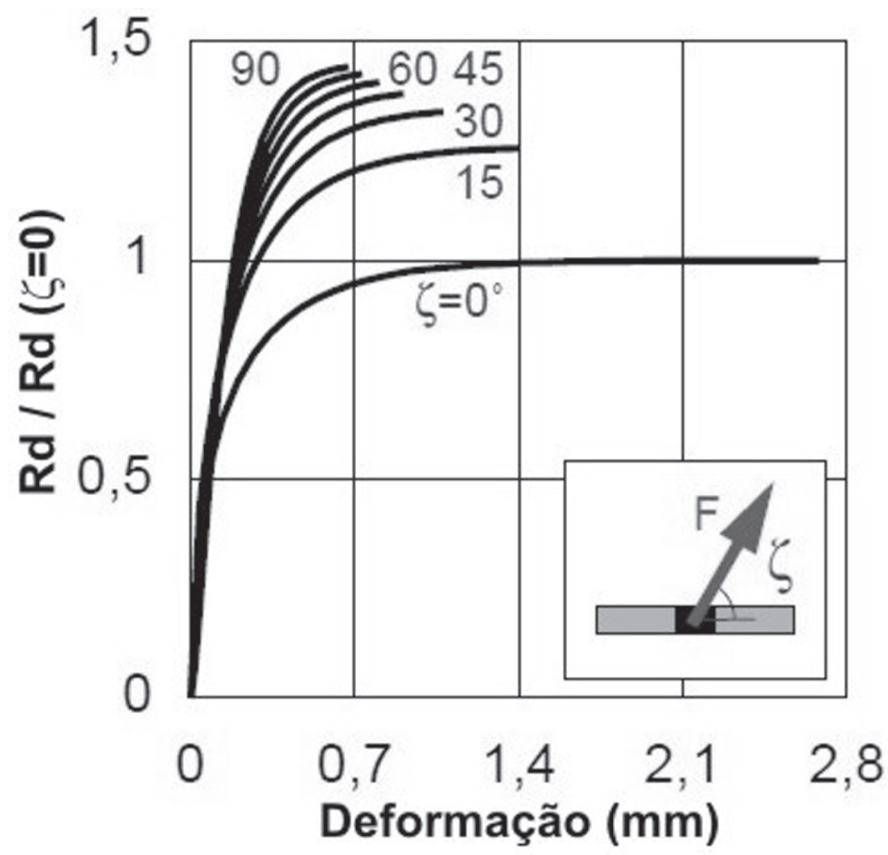

Figura 8. Resistência de projeto (Rd) em ângulo ( $\zeta$ ) de aplicação da carga (F) diferente de $0^{\circ}$, em relação à resistência de projeto quando $\zeta=0^{\circ}$.

(iv) Adicionalmente ao que mencionamos no item (iii) anterior, as juntas soldadas apresentam muito distintas resistências e 


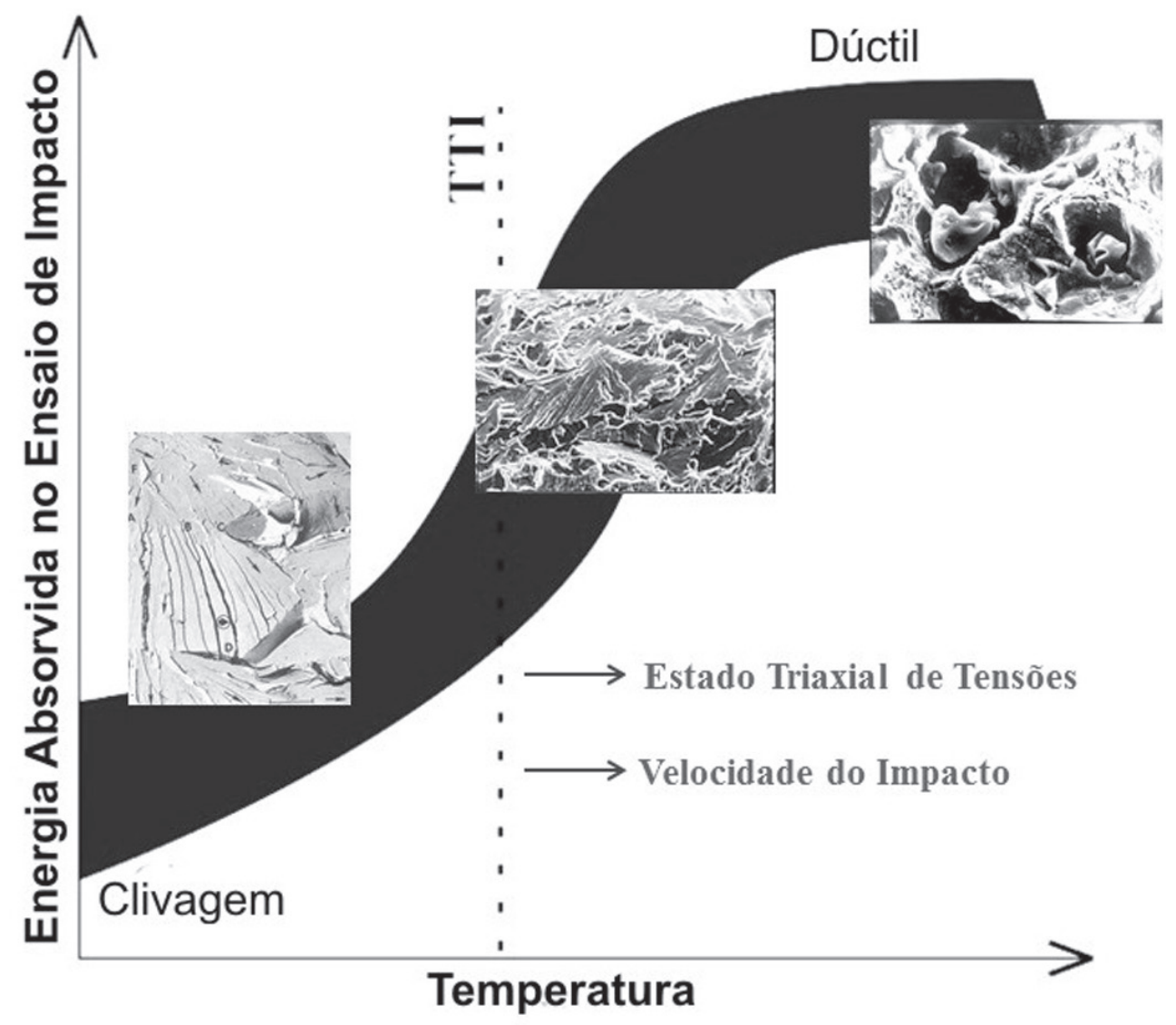

Figura 9. Ilustração esquemática do efeito da temperatura sobre o modo da fratura, além do estado triaxial de tensões e velocidade do impacto sobre a temperatura de transição ao impacto (TTI).

capacidades de deformação, dependendo da direção relativa da carga aplicada, cujos extremos são $90^{\circ}$ para junta transversal e $0^{\circ}$ para junta longitudinal, como podemos apreciar na Figura 8 [13]. Aliás, um fato que geralmente não é devidamente apreciado, é o da máxima deformação da solda (nesta figura) para $\mathrm{z}=0^{\circ}$ ser cerca de 4 vezes a deformação limite, quando este ângulo é $90^{\circ}$. Por outro lado, se a carga aplicada é normal ao cordão de solda, a sua resistência é aproximadamente $44 \%$ maior do que quando esta carga atua paralelamente ao seu eixo. Além disto, mesmo um pequeno ângulo aumenta significativamente a resistência de projeto, mas em contrapartida reduz substancialmente a capacidade de deformação total do cordão de solda.

(v) Vários tipos de defeitos ou falhas podem ocorrer no metal de solda ou na zona afetada pelo calor, tanto como consequência da operação de soldagem, quanto por questões metalúrgicas, ou de serviço. Existem, ainda, típicas descontinuidades no metal base que podem resultar em defeitos próximos ao cordão de solda, tal como decoesão lamelar — com a contração do metal de solda produzindo tensões ortogonais a planos de inclusões existentes no metal base.

(vi) Carregamento excessivo, ou indevido, ou ainda sub dimensionamento, podem provocar fratura em serviço. Nas estruturas tubulares, por exemplo, são identificados vários típicos modos de falhas, tais como por plastificação da corda ou por rasgamento ("puncionamento") da parede do perfil.

(vii) Com relação à fabricação dos componentes estruturais, modernamente existem diversas rotas para a laminação dos aços, as quais visam não somente o aumento da resistência à tração e limite de escoamento, mas refino dos grãos. As propriedades mecânicas extremas são exibidas pela tradicional laminação e normalização; pelos laminados com controle termomecânico e aqueles que, além de serem produzidos através deste último processo, sofrem ainda têmpera e auto-revenido. Analisando a razão entre os limites de escoamento e resistência à tração em função da primeira propriedade, os aços laminados com controle termomecânico apresentam maior ductilidade, ou seja, menor razão entre limite de escoamento e (limite da) resistência à tração, além desta razão ser menor do que 0,91 mesmo com limite de escoamento tão elevado quanto $460 \mathrm{MPa}$, o que não é alcançado pelos aços somente normalizados. Porém, provavelmente o mais espetacular efeito destes novos processos de produção, é obtido quando os aços sofrem laminação com controle termomecânico em combinação com têmpera e auto-revenido. Neste caso, mesmo aços com altos limites de escoamento podem ser soldados sem pré-aquecimento, desde que sejam controlados o nível de hidrogênio difusível e a energia de soldagem. Esta é uma direta consequência do aumento da resistência ter ocorrido com muito baixo carbono equivalente (CEV).

(viii) Finalmente - mas certamente sem esgotar o assunto-, por diversas razões certos membros da estrutura podem ter sofrido elevada deformação prévia antes de serem posicionados. Isto deve ser tratado com extrema precaução, pois apesar dos ganhos 
com a resistência, em geral há severa redução da ductilidade. Além disto, caso juntas soldadas sejam produzidas na ou próximo da região deformada, ocorrerá excessivo crescimento dos grãos e acentuadas quedas da resistência e da tenacidade.

Então, estes são alguns aspectos da questão "ductilidade" com carga relativamente estática. Porém, no caso das cargas serem de impacto, dentro de certos limites a estrutura e o material com que ela foi fabricada devem ainda continuar comportando-se de forma "dúctil". Evidentemente este assunto é extremamente complexo, mas alguns fatores que alteram a resistência ao impacto, podem ser satisfatoriamente compreendidos e utilizados de forma simples.

Por exemplo, é notável o conhecido efeito da redução da temperatura sobre a alteração do modo de fratura, desde por coalescência dos vazios (dúctil) para por clivagem (frágil), geralmente ocorrendo ao longo dos planos cristalográficos, tal como ilustramos na Figura 9. Entretanto, pelos menos dois outros fatores podem influenciar profundamente o modo como a fratura ocorre. Quanto maior a tendência ao estado triaxial de tensões -o qual, como mostramos, pode ser inadvertidamente provocado pelo projetista-, mais se amplia o campo da fratura frágil, com o deslocamento da temperatura de transição ao impacto (TTI) para maiores valores. Por outro lado, se a taxa de deformação aumenta, a TTI também é deslocada. Aliás, para aços ao carbono e baixa liga, as taxas de deformação podem ser classificadas em lentas (cerca de $10^{-3}$ por segundo) e dinâmicas (cerca de 10 por segundo). Neste intervalo, quanto menor o limite de escoamento do aço, maior a alteração na TTI.

Por outro lado, há muitos anos e com base em ensaios de grande número de diferentes aços não-austeníticos utilizados principalmente na indústria naval, um seminal trabalho [14] delimitou a influência da temperatura e da resistência do metal base, sobre a natureza da fratura e a necessária energia dinâmica para fraturá-lo.

Adicionalmente, as concentrações de tensões produzidas pelas juntas soldadas reduzem a resistência sob carregamento estático e em muito diminuem a resistência à fadiga dos membros que conectam e a intensidade da carga de impacto que suportam [1]. Por exemplo, apesar da aparente simplicidade das juntas soldadas de filete, modelagens por elementos finitos mostram que são extremamente complexos os sistemas internos de tensões através dos quais há transferência das cargas entre os membros.

Há, ainda, a questão relativa à resistência mecânica dos consumíveis utilizados para a soldagem dos aços estruturais. Geralmente mesmo no Brasil empregamos as expressões em inglês "matching" (ou resistência equivalente) para os consumíveis que possuem combinação dos limites de resistência à tração e de escoamento similar ou pouco maior do que a do metal base; "undermatching" para aqueles com menor resistência do que a do metal base e "overmatching" quando esta resistência é significativamente maior do que aquela do metal base.

Analisando os dois extremos, verificamos que uma direta vantagem do consumível "undermatching", é minimizar a tendência à trinca, tanto no metal de solda, quanto no metal base, particularmente sobre aços com limite de escoamento maior do que $480 \mathrm{MPa}$. A redução da tendência à trinca no metal base, através da utilização de um metal de solda mais dúctil, não é uma técnica muito conhecida, mas a razão é que o metal de solda coopera para redução do nível geral das tensões na junta soldada. Porém, como consequência das necessariamente maiores dimensões do cordão de solda, os custos da produção poderão ser mais elevados do que todos os outros casos.

Por outro lado, o emprego de "overmatching" reduz a massa do metal de adição, mas geralmente introduz indesejáveis e altas tensões residuais e pode requerer especial atenção quanto a defeitos com origem em fenômenos metalúrgicos, principalmente trinca induzida pelo hidrogênio. Além disto -e esta questão é deveras importante-, a menor área do cordão de solda na interface entre o metal de solda e o metal base reduz a tensão de cisalhamento admissível nesta região, eventualmente anulando a vantagem do emprego deste consumível.

\section{Juntas Estruturais Produzidas por Brasagem}

A brasagem é a mais antiga (e venerável) forma de unir metalurgicamente os materiais, sendo possivelmente praticada há mais do que 4500 anos. Presumimos ser desnecessário enfatizar, que em muitas situações este é o processo por excelência para fabricação de juntas estruturais, ou seja, que suportarão cargas significativamente elevadas. Isto se deve, principalmente, porque produz mínima distorção e é factível sobre diversos materiais, muitas vezes impossíveis de serem soldados, notavelmente nas áreas aeroespacial, eletroeletrônica e nuclear.

Juntas produzidas por brasagem formam um sistema heterogêneo e anisotrópico, consistindo do metal base; zona de difusão; eventualmente compostos intermetálicos e metal de adição. Porém, uma inquietante característica destas juntas, é a grande capacidade que elas têm de suportar cargas muitas vezes superiores a resistência à tração do metal de adição no estado "como fornecido".

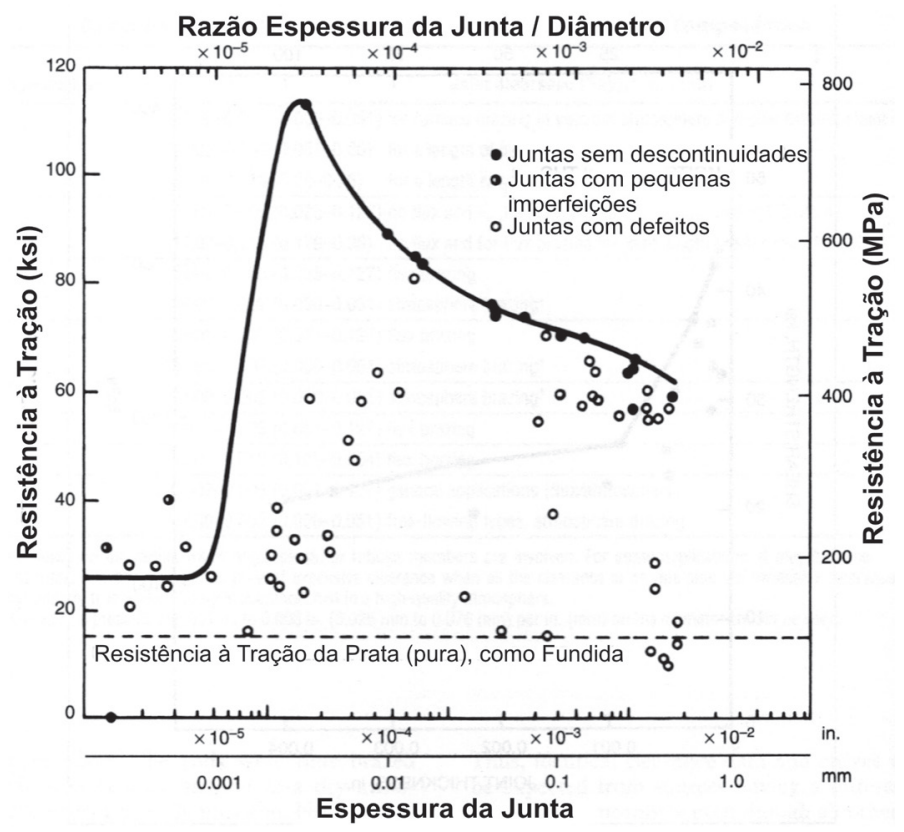

Figura 10. Resistência à tração de junta à topo produzida por brasagem (prata pura) sobre aço AISI 4340. 
A razão para este fato, é que usualmente são muito grandes as diferenças das propriedades elásticas e plásticas entre os metais base e de adição. Assim, com suficiente carga, o muito dúctil metal de adição tende a se deformar, mas o metal base o impede, pois ainda encontra-se no estado elástico. Isto reduz drasticamente a habilidade do metal de adição em se deformar plasticamente, levando-o a um estado triaxial de tensão.

Em juntas à topo, modelagens computacionais considerando a deformação plástica- que realizamos mostram, por exemplo, que há grande diferença entre uma folga (ou espessura da junta) de $0,05 \mathrm{~mm}$ e $1 \mathrm{~mm}$. Dados empíricos confirmam este fato, como ilustramos na Figura 10 [15] além de estar estabelecido que isto ocorre quando a folga e a razão entre o diâmetro - ou outra dimensão significativa do corpo de provae esta folga sejam adequados. Neste caso, o metal de adição é prata (pura) com resistência à tração de $120 \mathrm{MPa}$ e o metal base aço AISI 4340, com resistência à tração de aproximadamente $1400 \mathrm{MPa}$; com folga de $0,005 \mathrm{~mm}$, a resistência à tração da junta é cerca de $800 \mathrm{MPa}$ (!). Porém, folgas tão estreitas não são recomendáveis, ou mesmo possíveis de serem obtidas, devido tanto a problemas criados pelo método específico de brasagem - por exemplo inclusão de fluxo, quando for utilizado-, quanto a capilaridade, pois poderá não ocorrer completo preenchimento pelo metal de adição fundido. Decidir qual é a folga mais conveniente entre os metais base e de adição para uma dada aplicação é questão de difícil solução, pois muitas variáveis metalúrgicas estão envolvidas. Porém, mesmo que neste caso valores típicos encontrem-se entre 0,05 e $0,1 \mathrm{~mm}$, a resistência à tração desta junta ainda é superior a $400 \mathrm{MPa}$.

Consequentemente, juntas à topo produzidas corretamente por brasagem são muito mais resistentes do que os seus metais de adição, testados nas suas formas originais e sem constrangimento à deformação.

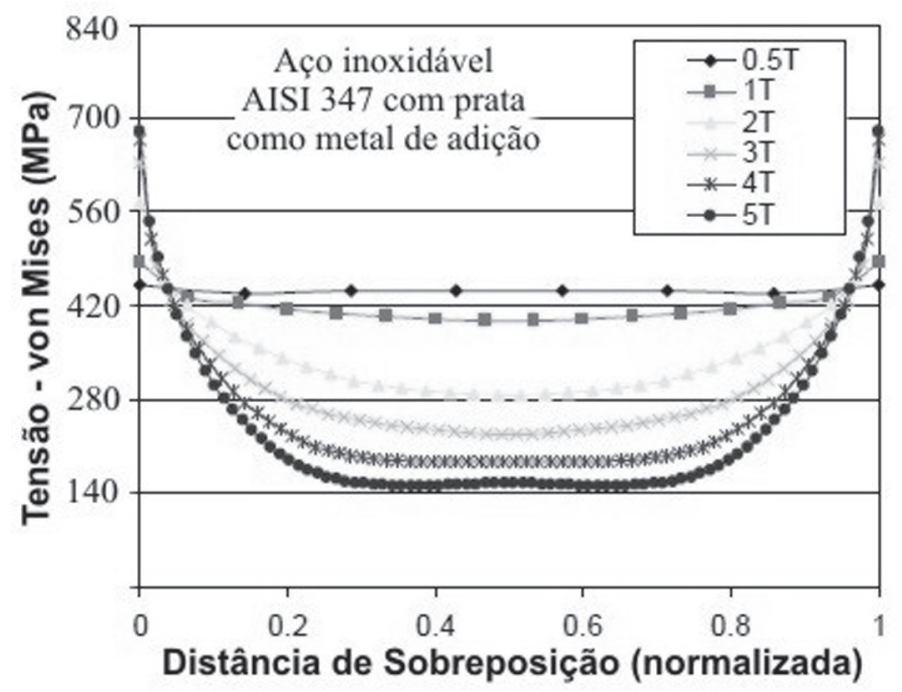

Figura 11. Distribuição da tensão de von Mises em junta sobreposta produzida por brasagem, como função do comprimento de sobreposição e da espessura das peças unidas

(T).
Por outro lado, juntas sobrepostas produzidas por brasagem apresentam um comportamento sui generis, tal como mostramos na Figura 11 [16], pois há excepcionalmente grande concentração de tensão nas suas extremidades, enquanto no seu interior a tensão é muito menor e uniformemente distribuída —nesta figura está mostrada a tensão de von Mises, com a tensão de cisalhamento comportando-se de forma similar. Além disto, para elevar a resistência de projeto, uma natural reação do projetista é produzir junta com mais longo comprimento de sobreposição. Entretanto, neste caso esta estratégia poderá não funcionar, pois a carga necessária para falha não depende exclusivamente deste comprimento, com a concentração de tensões nas extremidades aumentando proporcionalmente. Adicionalmente, há redução significativa da resistência de juntas sobrepostas conforme é maior a razão entre a folga e o comprimento de sobreposição.

Além destas questões, existindo apreciável formação de compostos intermetálicos nestas juntas, podem sofrer grande redução a resistência mecânica e/ou tenacidade.

\section{Conclusões}

Devido aos novos paradigmas impostos pela consideração da especificação da junta soldada como fruto de complexas interações entre os fenômenos metalúrgicos, os aspectos relativos aos mecanismos das conexões e o comportamento mecânico de todos os materiais envolvidos, mais do que nunca engenheiros de soldagem e projetistas de estruturas soldadas devem trabalhar cooperativamente desde a fase conceitual do projeto.

Desta forma, a junta soldada deverá ser tratada como parte indissociável dos conceitos gerais aplicados à estrutura, sendo indispensável que os envolvidos no projeto tenham muito boa formação nas áreas de metalurgia (geral), mecânica e soldagem, além de entenderem perfeitamente as sutis nuances deste assunto.

\section{Referências Bibliográficas}

[1] Machado, I. G. Dimensionamento de Juntas Soldadas de Filete: Uma Revisão Crítica. Soldagem \& Inspeção, 16(2): 189-201, Abr/Jun 2011. Nota: a versão impressa (ou digital em CD) deste artigo omitiu uma importante figura deste artigo; está correta a versão disponível na página da ABS (www.abssoldagem.org.br/).

[2] M. Matousek and Schneider, J., Untersuchungen Zur Struktur des Zicherheitproblemetal de solda bei Bauwerken, Institut für Baustatik und Konstruktion der ETH Zürich, Bericht No. 59, ETH, 1976. Citado por: Moan, T. Safety of Offshore Structures. Second Keppel Offshore \& Marine Lecture, NUS, Nov 2004.

[3] The Code of Hammurabi. Translated by L. W. King. Yale Law School - The Avalon Project (http://avalon.law.yale.edu/ subject_menus/hammenu.asp). Consultado em agosto/2012.

[4] E.R. Barker. Brittle Behavior of Engineering Structures, John Wiley \& Sons, 1957.

[5] AWS D1.1, Structural Welding Code - Steel. American Welding Society, Miami, FLA, USA, 2008.

[6] J. Lancaster. Engineering Catastrophes, Causes and Effects of Major Accidents. Abington Publishing, 1996. 
[7] ANSI/AISC 360-05. Specifications for Structural Steel Buildings. American Institute of Steel Construction, Inc. (AISC), EUA, 2005 ( $3^{\text {rd }}$ Printing, Apr 2007).

[8] International Institute of Welding - IIW (Comission XV). Design rules for arc welded connections in steel submitted to static loads. Welding in the World, 14 (5/6): 132-149, 1976.

[9] EN 1993-1-1: 2005. Eurocode 3: Design of steel structures - Part 1-1: General rules and rules for buildings.

[10] EN 1993-1-8: 2005. Eurocode 3: Design of steel structures

- Part 1-8: Design of joints.

[11] International Institute of Welding - IIW (Commission $\mathrm{XV}$ ). Static design procedure for welded hollow section joints - Recommendations. 3rd Edition. IIW Doc. XV-1281r1-08 and IIW Doc. XV-E-08-391, 2008.

[12] Blodgett, O. W. Structural Details to Increase Ductility of Connections. Structural Steel Educational Council. Steel Tips, pp. 1-12, Apr 1995.

[13] Ofner, R. EC 3 - Related Design of Shear Loaded Connections with Plastic Behaviour. Institute for Steel, Timber \& Shell Structures, TU-Graz, 2000.

[14] Pellini, W. S. Principles of Fracture Safe Design. Welding Journal, 50(3): 91s-109s, Mar and (4): 147s-162s, Apr, 1971.

[15] Brazing Handbook. American Welding Society, $5^{\text {th }}$ Ed., Miami, FL, 2007.

[16] Flom, Y. and Wang, L. Flaw Tolerance in Lap Shear Brazed Joints-Part 1. Welding Journal, 83(1): 32s-38s, Jan 2004. 